\title{
Improving lightweight materials processing for automotive by using intercritical annealing
}

\author{
Prita Dewi Basoeki ${ }^{1, a}$ \\ ${ }^{1}$ Mechanical Engineering Department, Engineering Faculty, Atma Jaya Catholic University of Indonesia, Jakarta, Indonesia.
}

\begin{abstract}
Fat men cannot run as fast as thin men, but we build most of our vehicles as though deadweight fat increased speed.... I cannot imagine where the delusion that weight means strength came from...." - Henry Ford. Fuel efficiency and safety innovations are the most important consumer consideration purchasing a car. Lightweight material contributes for increasing car efficiency as steel development for automotive material leads to "Formable-Weldable High Strength Steel" that possesses high strength without sacrificing its ductility and weld ability. During this research study indicates the difficulties in production of automotive materials through TRIP steel, as challenged by a Dual Phase Steel produced from an ordinary commercial C-Mn steel through an "Intercritical Annealing" route. Intercritical annealing had done at $740^{\circ} \mathrm{C}$ with variations in soaking time are followed by fast cooling in water. The Ferrite that surrounded by Martensite caused a significant impact to increase the strength of Dual Phase Steel, from 523.36 MPa to $1 \mathrm{GPa}$, with TEL 0.25 and UEL value of 0.2. By increasing the strength of Dual Phase Steel will impact the lightweight of the body frame of the car. With the higher the strength of Dual Phase Steel then the body of the car will improve lightweight.
\end{abstract}

\section{INTRODUCTION}

Fuel efficiency and safety innovations are the most important consumer consideration purchasing a car. The automotive industry is always looking for a breakthrough in improving fuel efficiency and improving material characteristics to meet those needs. Lightweight materials offer great potential for increasing car efficiency. The use of high strength steel is intended to reduce the weight of the car, because with high strength, thinner steel plates can be used. In addition, high strength steel has the ability to absorb large amount of energy. This is related to the ability of car frame to absorb energy in the event of an accident or known as crashworthiness. To achieve these efficiency improvement, automakers are developing a wide array of advanced technologies. These include improvements to engines, drivetrains, transmissions and aerodynamics and utilization of hybrid-or-full electric power systems in conjunction with alternative fuels. But the most fundamental and effective means of improving efficiency is accomplished by the reduction of vehicle mass.

Steel development for automotive material leads to development "Formable-Weldable High Strength Steel" possessing high strength without sacrificing its ductility and weld-ability. Currently, development of FormableWeldable High Strength Steel focused on TRIP (Transformation Induced Plasticity) Steel as on lab scale proves to have properties suitable for automotive materials. On industrial scale, however, TRIP production faces unavoidable obstacles. Firstly, the chemical composition of TRIP steel requires a considerably high percentage of Si that during steel production causes a formation of "Red Scales" on slab surface upon reheating prior to rolling process. Secondly, the microstructure of TRIP steel is complicated; it requires existence of a metastable Retained Austenite phase, which stipulates a considerably complicated heat treatment.

The challenges during the research study, difficulties in producing automotive materials through TRIP steel is challenged by the development a Dual Phase Steel (DP Steel) produced from an ordinary commercial C-Mn steel through an" Intercritical Annealing" route. Both of the constraints of TRIP steel are not at all owned by DP steel. The main drawback of DP steel over TRIP steel is that the total elongation, but its uniform elongation is not much different. This certainly makes the DP steel as the right automotive material because in the automotive industry the uniform elongation is more the determining factor of success in its forming processes. Intercritical annealing was done at $740^{\circ} \mathrm{C}$ with variations in soaking time followed by rapid cooling in water. Optical metallography examinations, X-Ray Diffractometry (XRD), Energy Dispersive Spectroscopy (EDS), and Mechanical Testing were undertaken to investigate a consistency between microstructure developed in produced Dual Phase Steel, its chemical composition and its mechanical properties.

Mega Tetsuya, et al. (2004), in JFE Technical Report, has successfully developed DP steel TS $980 \mathrm{MPa}$, with improved crashworthiness and weight reduction in automobile bodies [1]. This type of steel is applied to the body structure of the car on the door frame and the lower body, Figure 1.

\footnotetext{
* Corresponding author: pdbasoeki@atmajaya.ac.id
} 
Dual Phase Steels are steel with Ferrite and Martensite phase which are generally produced from the Intercritical Annealing process followed by rapid cooling. The unique combination of hard Martensite surrounded by Ferrite matrix has a high degree of elongation, and have an attractive combination between strength and ductility.

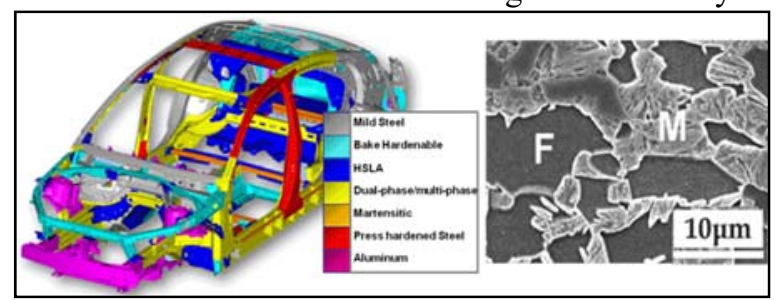

Figure 1. Usage of steels in a car body and a dual-phase microstructure [2]

\section{LITERATURE REVIEW}

In recent years, the Thermo-Mechanical Control Process (TMCP) process has grown rapidly in the production of steel plates that requires good mechanical properties. TMCP process is done through several stages of reheating, roughing, finish rolling and cooling to produce ferriteperlite steel. The metallurgical phenomenon during the TMCP process is phase transformation. The formation of Austenite and precipitate can be controlled in the stage of reheating, rolling and cooling processes, to obtain the desired mechanical properties.

The development of steel with a combination of strength and high ductility is the direction in automotive material research, which is focused on TRIP Steel and Dual Phase Steel. The difficulties that TRIP steel have, making this steel only being developed in the laboratory, while Dual Phase Steel shows more potential to be developed as automotive materials. The unique mechanical properties are obtained from C-Mn Steel by modifying the microstructure to Ferrie-Martensite, which is performed by heat treatment at intercritical annealing temperature followed by rapid cooling. Each stage of the heat treatment process will result in a microstructure, which will be closely related to the mechanical properties of Dual Phase Steel.

Intercritical Annealing is the heating process until a metal reaches its intercritical temperature intended to transform the Ferrite-Pearlite phase into the FerriteAustenite. The mechanism of the transformation depends greatly on the rate of heating. At the time of heating which the recrystallization of the Ferrite occurs, the Cementite in the Pearlite will transform into the Austenite and the Ferrite in the Pearlite will also transform into Austenite, which occurs upon entering the intercritical region.

The basic phenomenon of Austenite formation is nucleation and growth which is a diffusion mechanism. The transformation will begin in the Pearlite colony by Austenite nucleation at the Ferrite-Cementite grain boundary in Pearlite followed by a rapid growth due to soluble Cementite. In addition to the Austenite growth, Austenite also nucleates at the Ferrite grain boundary, the competition between these two factors is strongly influenced by the heating rate. A. Jacot and M. Rappaz (1999) have also succeeded in establishing a model for transforming the formation of Austenite from FerritePerlite steels by modeling the so-called Monte Carlo model developed as a normal Austenite grain growth simulation [3]. In the model the phase is assumed to be hexagonal mesh, which can grow in different directions. The topology of the hexagonal mesh model is shown in Figure 2.

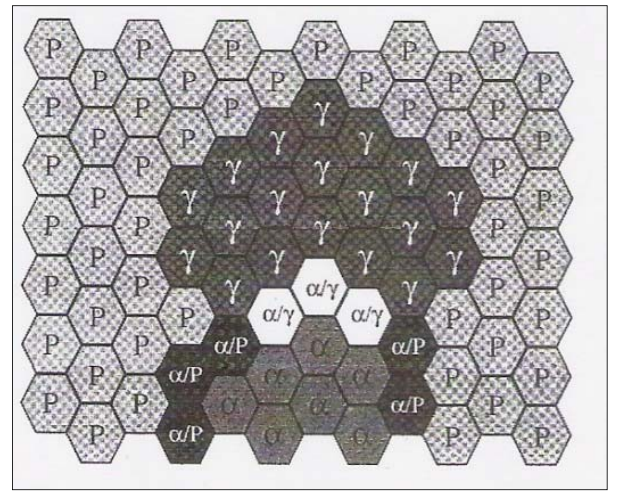

Figure 2. Illustration of hexagonal mesh Austenite nucleating sites in Ferrite-Pearlite Steel [3].

The illustration of the hexagonal mesh model shows that there are several different places for austenite nucleation and growth to occur in several domains: Ferrite $(\alpha)$, Austenite $(\gamma)$, Perlit (P), Ferrite/Perlit $(\alpha / \mathrm{P})$, Ferrite/Austenite $(\alpha / \gamma)$. The Monte Carlo model was developed with the assumption that austenite growth occurs normally based on hexagonal mesh whose growth can occur in different directions. Based on the Pritadewi Basoeki's research study (2007) and the proposed model of Jacot et al. (1999) and Zhang, et al. (2005), the phase transformation during the intercritical annealing process resulting in the decrease of the Ferrite grain surrounded by Martensite. In the initial conditions, the Pearlite colony is surrounded by Ferrite, during heating to the intercritical annealing temperature the Pearlite transforms into Austenite [4,5].

The heating process to the intercritical temperature is intended to convert the Ferrite-Perlit phase found in the $\mathrm{C}-\mathrm{Mn}$ steel plate into the Ferit-Austenite phase. The microstructure of Dual Phase Steel is a very simple microstructure which contains second phases, therefore its mechanical properties can be adjusted by modifying its microstructure. The second phase material and the second phase volume fraction can be controlled as well as the Ferrite phase, which corresponds both to the dislocation density and the carbon content to obtain the desired mechanical properties. The arrangement of the microstructure can be done by controlling the heating temperature as well as the heating time. The Martensite volume fraction increases with the intercritical temperature or the duration of heating. According to Prita Dewi Basoeki (2007), the maximum volume of Martensit which can be achieved is $40 \%$ with a heating temperature of $740^{\circ} \mathrm{C}$ and a heating time of $8-15$ minutes, followed by rapid cooling in water medium. However, at a higher intercritical temperature with a short heating time of 2 minutes, the Martensites formed will fall back down because all the carbides serving as Austenite nucleating sites are completely dissolved [4]. 


\section{METHODOLOGY}

The C-Mn Steel plate is selected as the base material because it is a simple alloy, containing a relatively small amount of carbon and manganese, $0.179 \% \mathrm{C}$ and $1,199 \%$ $\mathrm{Mn}$. The manufacturing process is hot rolling and classified as a conventional steel making process which is not too complicated. Both criteria provide opportunities and convenience to the local steel industry to produce it. Furthermore, C-Mn Steel plates are transformed into Dual Phase Steel through Intercritical Annealing process. The material used in this research is Steel C-Mn plate with 10 $\mathrm{mm}$ thick hot rolled plate, with a composition of $0,179 \%$ C-1,199\% Mn, which have Ferrite structure (light) and Perlit (dark The intercritical annealing process is performed by heating the specimen in the intercritical region of the two ferrite and austenite phases at a temperature of $740^{\circ} \mathrm{C}$, maintained for a moment at that temperature and then followed by rapid cooling. The expected steel phases formed from the process sequence are Ferrite and Martensite, although it does not rule out the presence of even smallest remaining Retained Austenite.

The heating temperature of $740^{\circ} \mathrm{C}$ is based on what Martensite volume fraction to be acquired, of course then associated with the strength to be achieved. A heating rate of $0.5^{\circ} \mathrm{C} / \mathrm{sec}$ andthe soaking time is between $5-15$ minutes with the purpose of understanding the mechanism/kinetics of Pearlite's transformation into Austenite. The target strength to be addressed in this research study is Dual Phase Steel with a strength of 1000 $\mathrm{MPa}$ or $1 \mathrm{GPa}$ and ductility 0.2 . Referring to the chemical composition of C-Mn steels and from the Fe-C-1,5Mn phase diagram, it can be predicted that at $740^{\circ} \mathrm{C}$ the Austenite formed is around $40 \%$.

Characterization with an optical/electron microscope (LOM/SEM), X-Ray Diffraction (XRD) and Energy Dispersion Spectroscopy (EDS) were performed on the Dual Phase Steel generated to obtain an overview of structural changes that occurred during the intercritical annealing process. Characterization conducted in this research study aims to evaluate the consistency of relations between structure, chemical composition and mechanical properties.

\section{RESULT AND DISCUSSION}

The relationship between the intercritical process parameters and the phase transformation will be the main topic. The discussion includes an analysis of the phase change when heated from room temperature to return to room temperature, after rapid cooling of intercritical annealing temperature.

The main purpose of the intercritical annealing process is to change the Ferrite and Pearlite in C-Mn Steel into Dual Phase Steel with Ferrite and Martensite phases. This transformation is began by first transforming the Ferrite and Pearlite phases into Ferrite and Austenite, which is carried out through the intercritical annealing.

With an increase in heating time on intercritical annealing, Ferrite grains tend to change to slightly equiaxial also smaller in size. Quantitatively it is shown by the result of diameter measurement of Ferrite and aspect ratio which is defined as the ratio of grain length measured in the transverse direction $(d t)$ with its longitudinal direction $(d l)$.

From the phase change that occurs, in addition to the change in size and shape of Ferrite grains, the Ferrite grain position also changes. In C-Mn Steel and Dual Phase Steels, heating up to 5 minutes result in most of the Ferrite grain boundary lies adjacent to other Ferrite grain boundaries, whereas after heating for 8 and 15 minutes almost all of Ferrite's grains are surrounded by the second phase, Figure 3. This Ferrite position will have an effect on the mechanical properties of Dual Phase Steel. Banded structure found in Steel C-Mn as a result of hot rolling, still present in Dual Phase Steels resulting from rapid cooling of intercritical annealing. The perfect intercritical annealing process will change the structure of the band of Pearlite to Austenite during heating. Furthermore, due to the rapid cooling Austenite will be transformed into a second phase of Martensite, while Ferrite will remain as Ferrite. The imperfect transformation from Pearlite to Austenite will result in a second phase, Martensite, also likely to still contain the Pearlite, Cementite or Retained Austenite. Austenite formation is strongly influenced by the duration of heating at intercritical annealing. The degree of Austenite formation during heating can be observed from the change in the resulting second phase volume fraction. The formation of Austenite will also affect the shape, size and phase around the ferrite.

During the intercritical annealing process, Austenite will continue to grow both as a result of changes in Pearlite and Ferrite until a balance fraction of Ferrite and Austenite volumes is achieved. At high temperatures ( $\left.780^{\circ} \mathrm{C}\right)$ the phase change is affected by carbon diffusion in Austenite, while at low temperatures $\left(730^{\circ} \mathrm{C}\right)$ more determined by Mn diffusion in Ferrite. Once the balance is reached, the mechanisms that occur in the nucleation and growth of the Austenite will produce the final structure of the equiaxial Ferrite surrounded by Austenite. Furthermore, the rapid cooling efect will transform the Austenite into Martensite so that the final structure of the Dual Phase Steel is a Ferrite surrounded by Martensite. The intercritical annealing process with a heating time of 5 to 15 minutes followed by rapid cooling, resulting in a Martensit volume fraction of $40 \%$.

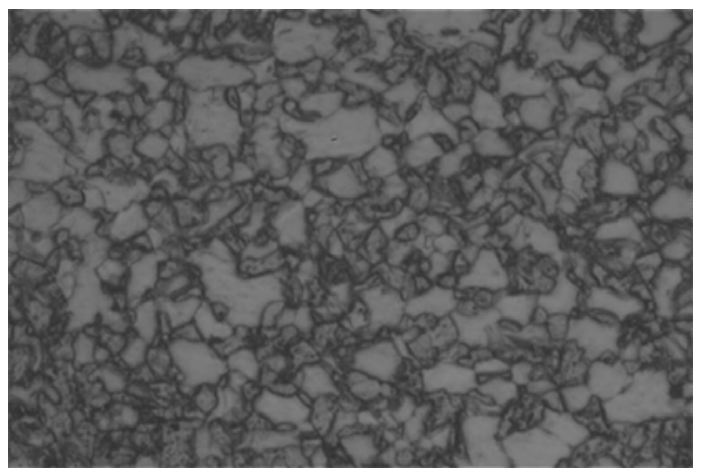

Figure 3. Microstructure of Dual Phase Steel 
The transformation of the C-Mn Steel microstructure into the microstructure of the Dual Phase Steels in the form of Ferrite surrounded by Martensite can be explained from the phenomenon of nucleation and growth of Austenite before transforming into Martensite. Prita Dewi Basoeki (2007) proposed a model of Ferrite-Pearlite transformation into Ferrite-Martensite as illustrated in Figure 4. During the intercritical annealing, Austenite was formed as a result of Pearlite and Ferrite transformation with the following stages [4]:

- $\quad$ Stage 1-Results of Perlit Transformation:

Austenite begins to nuclate at the boundary between Ferrite and Cementite in the Pearlite colony. Furthermore, the Austenite will grow and at the same time Cementite will dissolve resulting in the growth of Austenite. This stage will produce Austenite directly adjacent to Ferrite.

- $\quad$ Stage 2-Results of Ferritic Transformation:

This stage is the growth of Austenite by nucleation at the Ferrite grain boundary with adjacent Ferrite grains, or on a triple point of three Ferrite grains.

- $\quad$ Stage 3-Results of Austenite Growth:

The growth of Austenite in this stage will increase the amount of Ferrite surrounded by Austenite, in other words the number of Ferrite grains adjacent to the other Ferrite grains will be less.

- $\quad$ Stage 4-Results of Austenite Growth: With increasing Austenite holding time then Austenite will grow perfectly and decrease the Ferrite grains.

- $\quad$ Stage 5-Results of Austenite Transformation: At this stage it is followed by rapid cooling which will transform Austenite into Martensite, while Ferrite remains as Ferrite. The final microstructure of Dual Phase Steel formed as a result of rapid cooling is Ferrite surrounded by Martensite.

The formation completeness of the microstructure of the Dual Phase Steel whether the shape change, the size, the Ferrite position and Martensite depend on the holding time at intercritical temperature. This condition is very influential for the mechanical properties of Dual Phase Steel, both its tensile strength and its ductility.

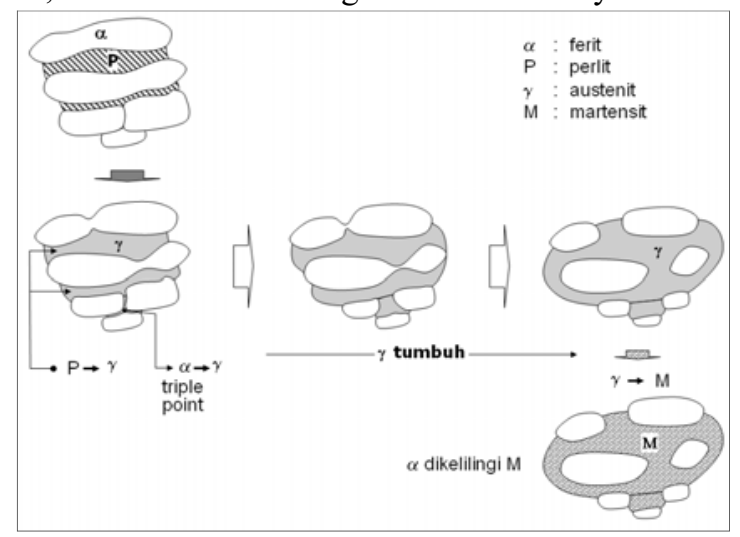

Figure 4. Schematic of Ferrite grain reduction mechanism surrounded by Martensite

Referring to a metal strengthening mechanism which states that the metal will be strengthen when the force required to drive the number of dislocations movement increases. When dislocation movement reaches the Ferrite grain boundaries will be more penetrable comparing to when the dislocation meets the grain boundary of Ferrite and Martensite. This means that to penetrate the Ferrite grain boundary requires a smaller force than to penetrate the grain boundary of Ferrite-Martensite. Thus, the more grain boundary between Ferrite and Martensite, the tensile strength of Dual Phase Steel will also increase. The position of Ferrite that surrounded the second phase turned out to give a significant increase in the strength of Dual Phase Steel, from 523.36 MPa to $1 \mathrm{GPa}$, with TEL 0.25 but the same relative TEL value of 0.2 . Increasing the strength of Dual Phase Steel that reach almost twice the C-Mn Steel will certainly give effect on the level of lightness of the body frame of the car. The higher the strength of Dual Phase Steel then the body of the car will also be increasingly light.

Reducing vehicle size and weight can significantly reduce fuel consumption. Every $10 \%$ of weight reduced from the average new car or light truck can cut fuel consumption by $6.9 \%$ (Bandivadekar, 2008). These mass reductions can be accomplished by: vehicle design changes, vehicle downsizing, lightweight material substitution [6].

\section{CONCLUSION}

The analysis of the characterization results in this research study show several important points which become the note as follows:

1.During the intercritical annealing process, Pearlite will transform into Austenite, and produce the final structure of equiaxed Ferrite surrounded by Austenite. The rapid cooling will transform the Austenite into Martensite, so that the final structure contained in Dual Phase Steel is Ferrite surrounded by Martensite.

2.The Ferrite surrounded by Martensite will provide a significant increase in strength.

3.The higher the strength of Dual Phase Steel then the body of the car will also be increasingly lightweight.

\section{REFERENCES}

1. M. Tetsuya, H. Kohe, K. Hidetaka, Ultra High Strength Steel Sheets for Bodies, reinforcement Parts, and seat frame Parts of Automobile, JFE Tech. Report, 4 (2004)

2. B. Zhu, Phase Field Modelling of Microstructure Evolution in low-carbon steels (DP600) during Intercritical Annealing, Ph.D. Project University of British Columbia, (2015)

3. A. Jacot, M. Rappaz, Modelling of Reaustenitization from the Pearlite Structure in Steel, Acta Materials, 46 (1998)

4. P.D. Basoeki, Metallurgical Aspects Of Process Changing For Commercial C-Mn Steel To Be A Dual Phase Steel For Automotive Materials, Proceeding International Mechanical Engineering and Engineering Education Conferences, (2016) 
5. J. Huang, W.J. Poole, M. Militzer, Austenite Formation during Intercritical Annealing, Metallurgicall and Materials Transaction (2004)

6. D. Codd, Advanced, Lightweight Materials Development and Technology for Increasing Vehicle Efficiency, KVA Incorporated, Escondido CA, (2008) 